\title{
Dissipation of spiroxamine residues in open field cucumber and dietary risk assessment
}

\author{
F. Malhat ${ }^{1, *}$, Ch. Anagnostopoulos ${ }^{2, *}$, S. El-Sayed' and S. Abdelsalam Shokr ${ }^{1}$
}

Summary Spiroxamine is one of the most used fungicides in the Mediterranean region, in significant uses such as open field cucumber. Residue trials in the Northern part of Egypt were conducted to investigate the dissipation of spiroxamine (SPX) in cucumbers according to the authorized Good Agricultural Practice (GAP) (1 x $75 \mathrm{~g}$ a.i. ha ${ }^{-1}$ at BBCH 85 to 89) and more critical use patterns. SPX was extracted from cucumbers using a modified QuEChERS protocol and residues were analyzed by liquid chromatography with tandem mass spectrometry (LC-MS/MS). The method was successfully validated with an LOQ of $0.001 \mathrm{mg} \mathrm{kg}^{-1}$. A steep decline of SPX residues in cucumbers fit a first-order decay process with a calculated $t_{1 / 2}$ of approximately 2 days and almost complete degradation (99\%) after 14 days. Chronic and acute exposure calculations were performed for cucumbers treated with SPX according to all tested GAPs employing two different approaches. In all cases a health risk after consumption of cucumbers was not identified.

Additional keywords: consumer exposure, field trial, kinetic model, LC-MS-MS, pre-harvest interval, spiroxamine

\section{Introduction}

Cucumber (Cucumis sativus L., Cucurbitaceae) is a popular vegetable, and a significant part of the Mediterranean diet, being a source of vitamins and minerals, and is consumed mostly raw. The cultivation of the vegetable in warm climates is susceptible to various disease infestation, especially under open field conditions, with fungi diseases such as Fusarium oxysporum f.sp. cucumerinum, Alternaria alternata, Verticillium sp., Botrytis cinerea, Pseudoperonospora cubensis, Erysiphe cichoracearum, Sphaerotheca fuliginea and Leveillula taurica being some of the most serious problems, effecting both yield and quality of the final product.

To protect cucumber cultivation in Egypt, several fungicides (active substances)

1 Pesticide Residues and Environmental Pollution Department, Central Agricultural Pesticide Laboratory, Agricultural Research Center, Dokki, Giza 12618, Egypt.

2 Benaki Phytopathological Institute, Scientific Directorate of Pesticides Control and Phytopharmacy, Laboratory of Pesticides Residues, 8 St. Delta Street, GR14561 Kifissia, Attica, Greece.

* Corresponding authors: farag_malhat@yahoo.com c.anagnostopoulos@bpi.gr are authorized by the Egyptian Agricultural Pesticide Committee (APC) with spiroxamine (SPX) being one of them. SPX is authorized in many countries for various uses such as Uncinula necator in grapes (Hellenic Ministry of Rural Development and Food), bananas (European Food Safety Authority, 2015) and cereals in combination with triazole fungicides, like prothioconazole (European Food Safety Authority, 2010). Although, these authorized uses are supported by residue data provided by the industry, in open literature, research studies investigating the residue behavior of SPX in cucurbits are not available. However, studies are available on the investigation of the residue behavior in grapes (Tsiropoulos, 2005a; Tsiropoulos, 2005b), strawberries (Malhat, 2020) or on the metabolism in various crops (Buerge et al., 2016) and soil (Rosales-Conrado, 2009; Sukul et al., 2010; Baćmaga et al., 2019). In addition, several studies are available assessing parameters related to the efficacy of the active substance, in general (Miller and Gubler, 2004) or in specific crops like citrus (D'Aquino et al., 2011).

Residues of SPX are detected in various food commodities of plant origin like bananas, peppers, grapes, wheat and melons 
(European Food Safety Authority, 2020), animal origin like eggs (Pereira, 2014) and environment samples like pollen of field bean, strawberry and raspberry (Tosi, 2018; David, 2020), and water (Tokatli, 2020). Exposure to this compound might have detrimental health effects on humans, thus dietary toxicological reference values are set. An acceptable daily intake (ADI) of $0.025 \mathrm{mg} / \mathrm{kg}$ bw/d by applying an assessment factor of 100 to the no-observed-adverse-effect level (NOAEL) from the 1-year dog study and an acute reference dose (ARfD), is $0.1 \mathrm{mg} / \mathrm{kg} \mathrm{bw}$ derived from the acute neurotoxicity study in rat, with a safety factor of 100 are adopted at European (EU) level (European Food Safety Authority, 2010; European Commission, 2020). Therefore, it is important to minimize these residues to a reasonable level by establishing maximum residue limits (MRLs) in cucumbers. After a search by the authors in several databases (BCGlobal's Pesticide Database; Codex Pesticides Residues in Food Online Database; European Commission 2020), established MRLs on SPX in cucumber were not identified. In the EU the default value of $0.01 \mathrm{mg} \mathrm{kg}^{-1}$ is used for enforcement (European Commission, 2016).

In this study, the dissipation kinetics of SPX in Egypt following several use patterns, was investigated. A risk assessment of the residues resulting from these practices was conducted and the safety of the maximum residues was estimated at several Pre-Harvest intervals (PHIs).

\section{Materials and Methods}

SPX was applied using a commercial EC formulation, in outdoor field trials following several GAPs at Matshtul district (Sharkia governorate, Egypt) in one growing season (2018-2019). According to regulatory guidelines (OECD, 2009) in the case of outdoor crops the results on pesticide residues can be extrapolated to other regions with the same climate, this being a common practice in the EU (European Commision, 2017; European Commission, 2013). Although the Mat- shtul district is on the Mediterranean part of Egypt, residue studies of SPX in other Mediterranean counties, especially EU countries, were not available from the literature and hence a comparison of the results was not possible.

A randomized block design $\left(15 \mathrm{~m}^{2}\right.$ plot size) was employed for the plot/crop layout with triplicate treatments including a buffer area with no pesticide application. An additional plot was included in the design as blank control plot. The pesticide was applied once, twice or three times at a single (75 $\mathrm{g}$ a.i. ha-1) or double (150 $\mathrm{g}$ a.i. ha-1) dose using a high-pressure knapsack sprayer. The first spray was applied at BBCH $85-89$ (half of the size of fruit maturation) and with a 14 days interval for the GAPs with more applications. The authorized GAP (1x75 $\mathrm{g}$ a.i. $\left.\mathrm{ha}^{-1}\right)$ and additional more critical use patterns (double dose rate or 2-3 applications or both) were investigated as to estimate the final residue and risk to the consumer from a potential misuse or emergency applications due to unexpected disease or pattern that may be authorized in the future.

For each field, fruit samples $(2 \mathrm{~kg})$ were randomly collected at 3 and 7 days, except from the fields in which application was conducted according to the authorized ( $1 \mathrm{x}$ $75 \mathrm{~g}$ a.i. $\mathrm{ha}^{-1}$ ) and the double dose pattern (1 x $150 \mathrm{~g}$ a.i. $\mathrm{ha}^{-1}$ ). In the latter fields, samples were collected at $0,1,3,7,10$ and 14 days after the final application, packed in wellaerated bags and brought to the laboratory in the same day. The storage period between harvest and analysis was less than 1 week, thus investigation of the stability of residues during storage is not required (European Commision 1995; OECD 2007). For the analysis of the samples the (Quick, Easy, Cheap, Effective, Rugged and Safe) QuEChERS extraction procedure (EN-15662 2009) as previously modified by the authors (Malhat et al. 2020) was used. Related to the materials used in the analysis, SPX certified reference standard (99\%) was bought from Dr Ehrenstorfer (Augsburg, Germany), all solvents (acetonitrile and methanol) were HPLC grade and purchased from Sigma Al- 
drich Chemical Co., analytical grade sodium chloride $(\mathrm{NaCl})$, magnesium sulfate anhydrous $\left(\mathrm{MgSO}_{4}\right)$ (dried at $450^{\circ} \mathrm{C}$ overnight before use), trisoduim citrate dehydrates and disodium hydrogen citrate sesquihydrate were supplied from Merck (Darmstadt, Germany). The sample preparation is described below for completeness:

Ten grams of the homogenized subsample was weighted into $50 \mathrm{~mL}$ centrifuge tube along with $10 \mathrm{~mL}$ of acetonitrile and vortexed for $2 \mathrm{~min}$. Hereafter, $4.0 \mathrm{~g}$ of $\mathrm{Mg}$ $\mathrm{SO}_{4}$ anhydrous, $1.0 \mathrm{~g}$ of $\mathrm{NaCl}, 1.0 \mathrm{~g}$ tri-sodium citrate (dihydrate) and $0.5 \mathrm{~g}$ sodium hydrogencitrate sesquihydrate were added and the tube was shaken intensively for 2 min. by hand. The sample was then centrifuged at $4800 \mathrm{rpm}$ for $5 \mathrm{~min}$ for phase separation and an aliquot of $200 \mu \mathrm{L}$ of supernatant was diluted with $800 \mu \mathrm{L}$ acetonitrile, filtered with a PTFE $(0.2 \mu \mathrm{m})$ syringe filter and the samples were ready for injection in the LC-MS/MS. Based on this procedure, the $C\left(\mathrm{mg} \mathrm{kg}^{-1}\right)$ in the sample correspond to 5 times the concentration in the extract $(\mu \mathrm{g}$ $\mathrm{mL}^{-1}$ ) analyzed. An LC-MS/MS system with an Exion LC system coupled to QTRAP mass spectrometer (QTRAP $6500^{+}$, AB SCIEX) was used for the analysis of SPX residues. A Synergi $C_{18}$ column, $2.5 \mu \mathrm{m}$ Fusion-RP $100 \AA$, 3.0 $x 50 \mathrm{~mm}$ (Phenomenex) was used for chromatographic separation. The column temperature was held at $40^{\circ} \mathrm{C}$. Mobile phases consist of water $(A)$ and methanol $(B)$ both containing $5 \mathrm{mM}$ ammonium formate.

Elution was performed at gradient mode as follows: a ratio of $20 \%$ for eluent $B$, running for (0-1.0 minutes), 20-100\% B (1-8 min.), and then $20 \% \mathrm{~B}(8.05-10 \mathrm{~min}$.). at a flow rate of $0.4 \mathrm{~mL} / \mathrm{min}$. The injection volume was 2 $\mu \mathrm{L}$. SPX was eluted at $5.5 \mathrm{~min}$. The LC-MS/ MS was operated using electrospray ioniza- tion (ESI) in the positive ion mode with multiple reaction monitoring (MRM) in the scan mode. Sources and gas parameter were optimized as follows: ion spray voltage 5500 $V$ for ESI (+); ion source temperature $400^{\circ} \mathrm{C}$; curtain gas 20 psi; collision gas medium; nebulizer gas and auxiliary gas 35 psi. The Analyst software (Version 1.7.1, AB Sciex) was used for the instrument setting, data acquisition and processing. The specific parameters are given in Table 1.

The method was validated, determining the limit of quantitation (LOQ), accuracy and precision (recoveries from fortified samples), matrix effect (due to co-extractives) and linearity (in solvent and matrix) as per SANTE guideline (Commission 2017). The matrix effect (ME) was evaluated according to the following equation:

$$
\% M E=100\left(\frac{M_{\text {matrix }}-M_{\text {solvent }}}{M_{\text {matrix }}}\right)
$$

where $\% M E$ is the \% estimation of the matrix effect, $M_{\text {matrix }}$ and $M_{\text {solvent }}$ are the slopes of calibration curves in cucumber extract and acetonitrile, respectively. If the ME value is between the threshold of $\pm 20 \%$, matric effect can be considered not significant (Kmellár et al., 2008; Pizzutti et al., 2009). In addition to the above threshold, according to Ferrer et al. (2011) matrix effect can be considered as soft when ME is calculated between $20-50 \%$ and strong above $50 \%$ or below $-50 \%$.

The dissipation rate of SPX in cucumber was evaluated by subjecting the data to a first-order kinetics equation:

$$
C_{t}=C_{0} e^{-k t}
$$

Table 1. LC-MS/MS optimization parameters for SPX.

\begin{tabular}{l|c|c|c|c|c|c|c}
\hline $\begin{array}{l}\text { Precursor } \\
\text { ion (Q1) }\end{array}$ & $\begin{array}{c}\text { Product } \\
\text { ions (Q3) }\end{array}$ & $\begin{array}{c}\text { Retention } \\
\text { time }\end{array}$ & $\begin{array}{c}\text { Declustering } \\
\text { potential (DP) }\end{array}$ & $\begin{array}{c}\text { Entrance } \\
\text { Potential (EP) }\end{array}$ & $\begin{array}{c}\text { Collision } \\
\text { Energy (CE) }\end{array}$ & $\begin{array}{c}\text { Collision Cell } \\
\text { Exit Potential } \\
\text { (CXP) }\end{array}$ & Purpose \\
\hline 298.3 & 144.2 & 5.5 & 80 & 10 & 27 & 4 & quantitation \\
298.3 & 100.2 & 5.5 & 80 & 10 & 50 & 4 & qualifier \\
\hline
\end{tabular}


where $C_{t}$ represents the concentration (mg $\mathrm{kg}^{-1}$ ) of SPX at time (t), $\mathrm{C}_{0}$ represents the initial concentration $(\mathrm{mg} / \mathrm{kg}$ ) of SPX after application, and $\mathrm{k}$ is the dissipation coefficient in day 0 .

The persistence of SPX is generally expressed in terms of half-life, $\mathrm{t}_{1 / 2}$ or $\mathrm{DT}_{50}$, i.e., time for the disappearance of pesticide to $50 \%$ of its initial concentration and was calculated from the $k$ value as following:

$$
t 1 / 2=\ln 2 / k
$$

To ensure that a health risk is not related to the current use, a dietary consumer risk assessment was performed, including as input values for the exposure the residue levels from all PHIs related to the authorized GAP; for the hazard the ADI $(0.025 \mathrm{mg} / \mathrm{kg}$ bw/d) and ARfD (0.1 mg/kg bw/d) was taken into consideration (European Commission 2020; European Food Safety Authority, 2010).

The long-term dietary exposure to SPX from cucumbers consumption was estimated using the following equations (Wang et al., 2015; Zhu Xiaodan et al., 2016) (FAO, 2009; FAO/WHO, 1988):

$$
\mathrm{NEDI}=\mathrm{CRL} \times \frac{\mathrm{F}}{60}
$$

where NEDI is national estimated daily intake ( $\mathrm{mg} / \mathrm{kg}$, bw), CRL is residue levels ( $\mathrm{mg} /$ $\mathrm{kg}$ ); $\mathrm{F}$ is the cucumber average consumption data (g/d) according to WHO cluster diet G06 (IEDI 2014; WHO 2013a; WHO 2013b) and 60 is the body weight $(\mathrm{kg})$.

and

$$
\mathrm{RQ}=\frac{\mathrm{NEDI}}{\mathrm{ADI}}
$$

where $\mathrm{RQ}$ is the risk quotient and $\mathrm{ADI}$ is the acceptable daily intake $(\mathrm{mg} / \mathrm{kg}$, bw). Whereas $R Q$ value higher than $1(\geq 100 \%$ of $A D I)$ an unacceptable chronic risk to the consumer is identified.

Additionally to the above approach, since EU is a significant market for Egyptian cucumbers, the deterministic model EFSA
PRIMo revision 3.1 (European Food Safety Authority, 2019) which is the calculation model used on EUMRLs setting, was also employed.

\section{Results and Discussion}

The applied method is considered suitable for the determination of SPX in cucumbers at an LOQ of $0.001 \mathrm{mg} \mathrm{kg}^{-1}$ according to EU standards (SANTE/11813/2017, 2017). The LOQ is 10 times below the default EUMRL of $0.01 \mathrm{mg} \mathrm{kg}^{-1}$ and is suitable for investigation of the degradation of the compound at very low levels. The mean recovery values were between 99 and 105\%. For the precision, both repeatability and reproducibility were estimated and were found acceptable, with $\mathrm{RSD}_{\text {r }}$ of below $17 \%$ for repeatability (at all fortification levels) and $\mathrm{RSD}_{\mathrm{R}}$ of $11 \%$ (calculated at $0.1 \mathrm{mg} \mathrm{kg}^{-1}$ ) for "day to day" reproducibility. Good linearity using 5 levels (0.001, 0.01, 0.02, 0.05, and $\left.0.1 \mathrm{mg} \mathrm{L}^{-1}\right)$ was obtained in both solvent and matrix with the coefficients of determination $\left(R^{2}\right)$ higher than 0.99. Matrix effect was found to be negligible (ME below 20\%). Recovery and precision data are presented in Tables 2 and 3. A visual comparison of the chromatograms in blank cucumber and spiked sample at $0.001 \mathrm{mg} \mathrm{kg}^{-1}$ (validated LOQ) is presented in Fig. 1.

The dissipation rate of SPX in cucumbers was calculated based on the experiment performed with the authorized GAP from residues measured at the day of the last application (0 day), and 1, 3, 7, 10 and 14 days later. Residues were not detected in the control samples. In the samples col-

Table 2. Recovery percentage and relative standard deviation of SPX in cucumber $(n=6)$.

\begin{tabular}{l|c|c}
\hline $\begin{array}{l}\text { Spiking level } \\
\left(\mathrm{mg} / \mathrm{kg}^{-1}\right)\end{array}$ & Recovery (\%) & RSD (\%) \\
\hline 0.001 & 98 & 17 \\
0.01 & 96 & 15 \\
0.1 & 97 & 10 \\
\hline
\end{tabular}


Table 3. Recovery $\mathrm{RSD}_{\mathrm{r}}$ and $\mathrm{RSD}_{\mathrm{R}}$ values obtained from analysis of cucumber samples spiked with SPX at $0.1 \mathrm{mg} \mathrm{kg}^{-1}(n=6)$.

\begin{tabular}{l|c|c|c}
\hline $\begin{array}{l}\text { Analysis } \\
\text { day }\end{array}$ & Recovery $\%$ & $\mathrm{RSD}_{\mathrm{r}} \%$ & $\mathrm{RSD}_{\mathrm{R}} \%$ \\
\hline 1 & 95 & 11 & \\
2 & 99 & 6 & 11 \\
3 & 94 & 3 & \\
\hline
\end{tabular}

lected at the day of the last application (day 0) residues were $0.67 \mathrm{mg} \mathrm{kg}^{-1}$. In the $1^{\text {st }}$ day a degradation of $13 \%$ was observed with a rapidly and gradually decrease of the residues until day 7 , with residue levels declining down to $0.041 \mathrm{mg} \mathrm{kg}^{-1}$ (decline of $94 \%$ compared to the initial concentration). After this point and with a stable but less steep degradation, the residue levels dropped to

A. Blank cucumber matrix

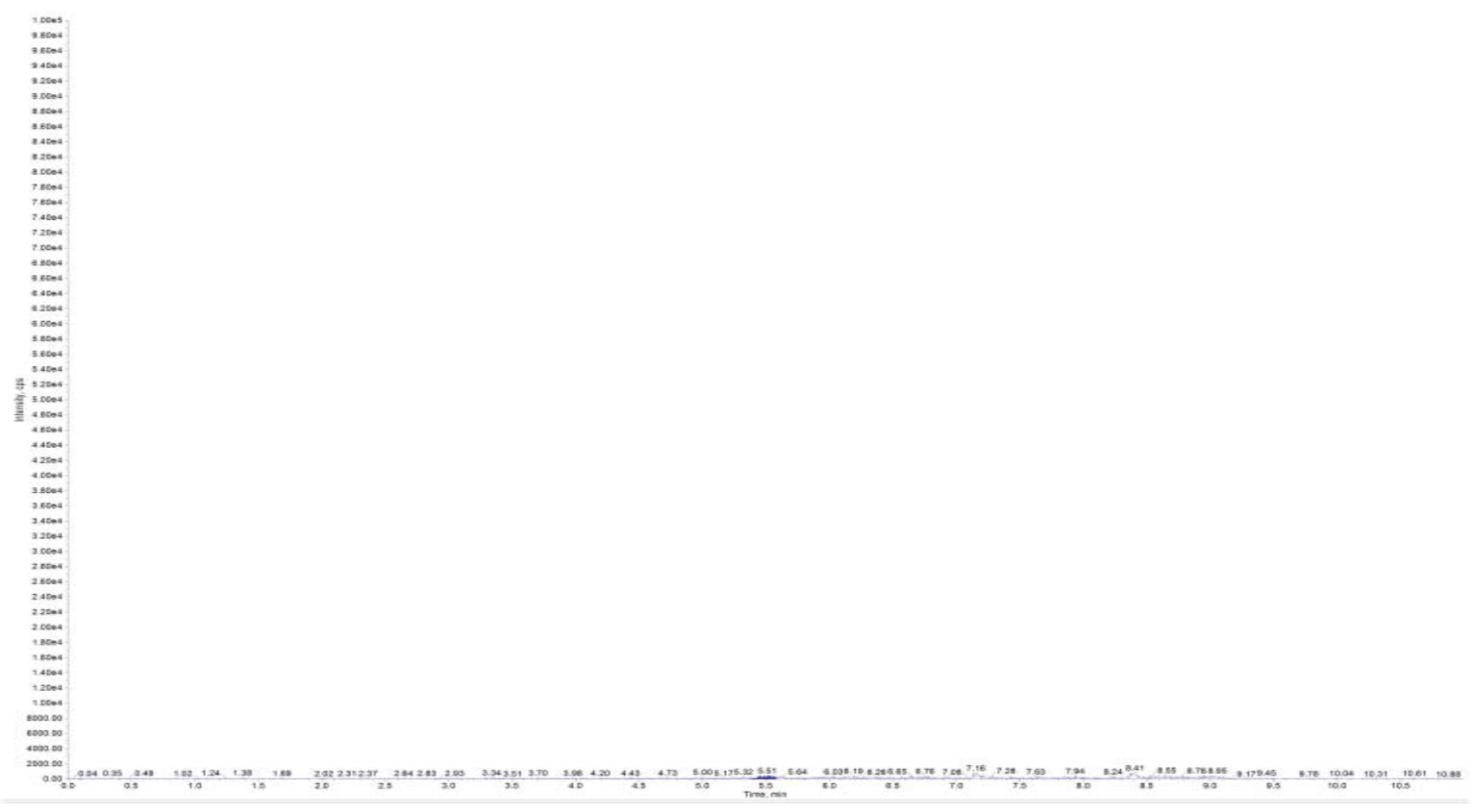

B. Spiked cucumber sample $0.001 \mathrm{mg} \mathrm{L}^{-1}$

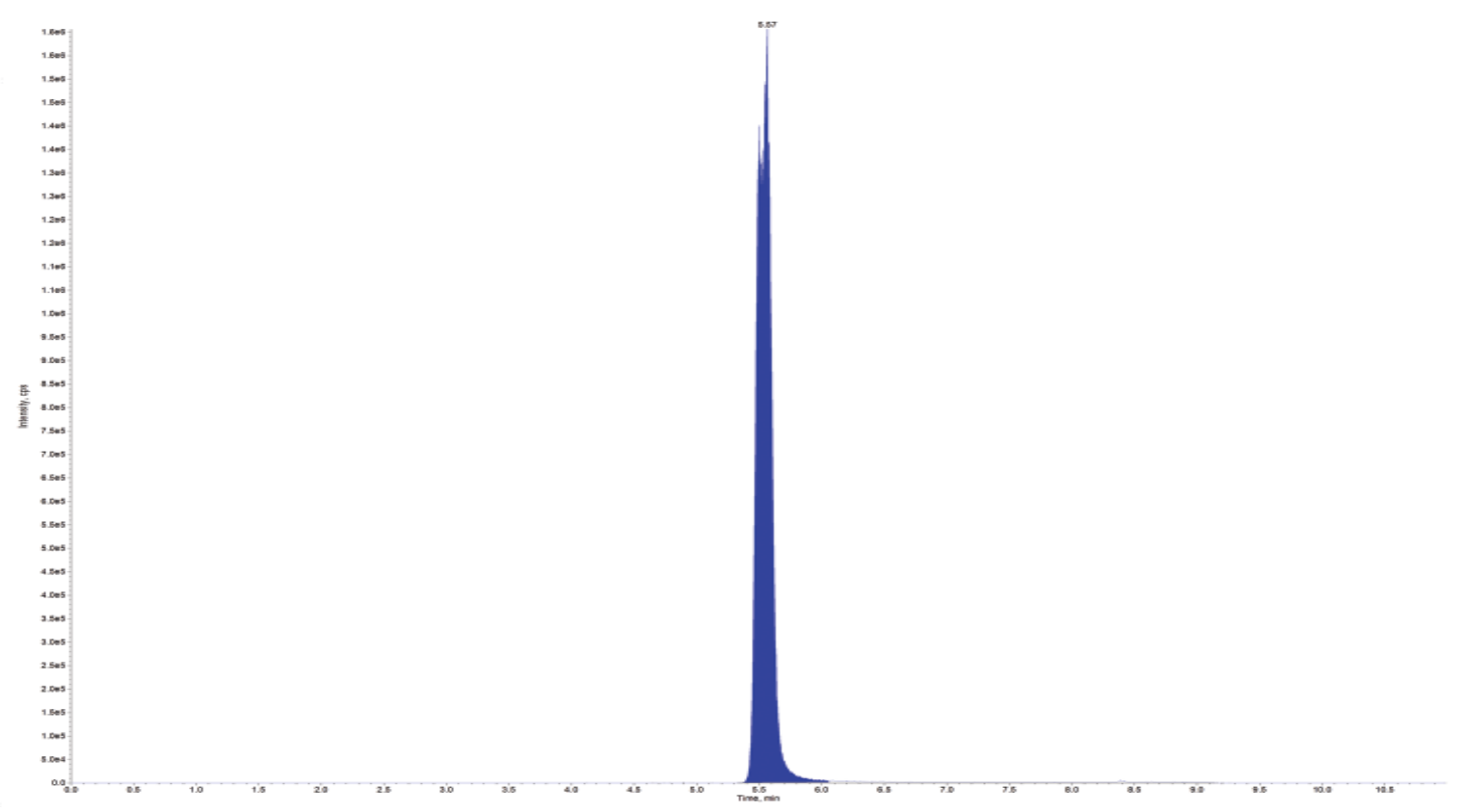

Figure 1. LC-MS/MS chromatograms of SPX (A) Cucumber blank (B) Spiked cucumber sample $\left(0.01 \mathrm{mg} \mathrm{L}^{-1}\right)$. 
$0.003 \mathrm{mg} \mathrm{kg}^{-1}$, representing almost complete degradation (>99\%) at 14 days. Based on this behavior the half-life $\left(t_{1 / 2}\right)$ was calculated at approximately 2 days (1.95) with a good exponential correlation between concentration and time $\left(r^{2}>0.9953\right)$ to be observed. A graphical visualization of the dissipation pattern is presented in Fig. 2. The published work on the application of SPX in crops is scarce. In the few studies available under Mediterranean conditions, its half-life is 7 days in grapes (Tsiropoulos, 2005a) and 4.71 days in strawberries (Malhat, 2020).

The effect of the different rates and applications was also examined by comparison of the residue levels at PHI of 3 and 7 days from different use patterns. The results are

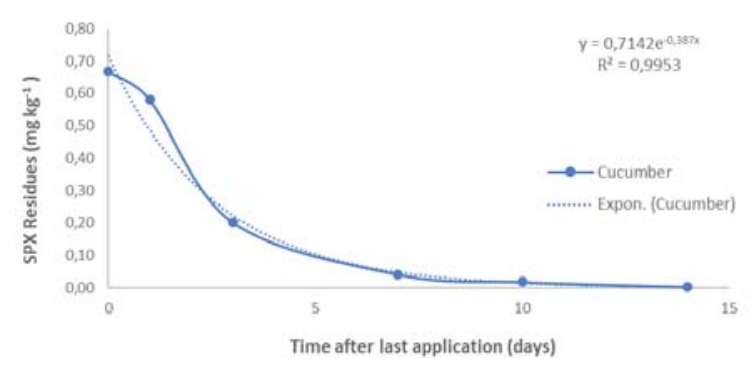

Figure 2. Dissipation pattern of SPX in/on cucumbers at the authorized GAP. presented in tabular form in Table 4. In some cases, despite the increase of dose or number of applications, the residue levels were significantly lower compared to the less critical cases, whereas in principle an increase should have been observed. Since from the experimental conditions no error was observed or an extreme environmental parameter was not recorded, this is considered as a variability of the data set as a whole, therefore not rejected. At a $\mathrm{PHI}$ of 3 days, residue levels were $0.23 \pm 0.005 \mathrm{mg} \mathrm{kg}^{-1}$ when applied at a use pattern of $2 \times 75 \mathrm{~g}$ a.i. ha- ${ }^{-1}$ and $0.43 \pm 0.026 \mathrm{mg} \mathrm{kg}^{-1}$ at twice the dose rate, indicating $47 \%$ increase in residues due to dose increase. Similar in the case with 3 applications, in which the increase was higher (68-75\%). A correlation between the number of applications and the residue levels cannot be identified. In both levels in the use patterns with 3 applications, the residue levels at 3 days were lower or similar compared to the ones with 2 applications. Based on the above, the number of applications seem not to have a significant effect on the final residue. This can be confirmed by the results from both sampling days ( 3 and 7 days $\mathrm{PHI}$ ).

Due to the absence of established MRL for SPX in cucumbers, a comparison is only

Table 4. Residues and \% comparison of SPX in cucumbers at 2 different dosage and number of applications, more critical that the authorized GAP (1 x $75 \mathrm{~g}$ a.i ha-1 $)$.

\begin{tabular}{|c|c|c|c|c|c|c|}
\hline $\begin{array}{l}\text { Dosage } \\
\text { (g a.i/ha) }\end{array}$ & $\mathrm{n}^{\mathrm{a}}$ & $\mathrm{PHI}$ & $\begin{array}{c}\text { Residues } \\
(\mathrm{mg} / \mathrm{kg} \pm \mathrm{SD})\end{array}$ & $\begin{array}{c}\text { Residue decline from } \\
\text { previous sample } \\
\text { point }^{b}\end{array}$ & $\begin{array}{l}\text { Residue in- } \\
\text { crease due to } \\
\text { dose rate }\end{array}$ & $\begin{array}{c}\text { Residue increase due } \\
\text { to number of appli- } \\
\text { cations }^{d}\end{array}$ \\
\hline \multirow{4}{*}{75} & \multirow{2}{*}{2} & 3 & $0.23 \pm 0.005$ & \multirow{4}{*}{$95 \%$} & & \\
\hline & & 7 & $0.012 \pm 0.001$ & & & \\
\hline & \multirow{2}{*}{3} & 3 & $0.11 \pm 0.009$ & & & $-116 \% \mathrm{e}^{\mathrm{e}}$ \\
\hline & & 7 & $0.014 \pm 0.011$ & & & $14 \%$ \\
\hline \multirow{4}{*}{150} & \multirow{2}{*}{2} & 3 & $0.43 \pm 0.026$ & \multirow{3}{*}{$98 \%$} & $47 \%$ & \\
\hline & & 7 & $0.010 \pm 0.002$ & & $-20 \%^{f}$ & \\
\hline & \multirow{2}{*}{3} & 3 & $0.42 \pm 0.032$ & & $75 \%$ & $-4 \% \mathrm{e}^{\mathrm{e}}$ \\
\hline & & 7 & $0.044 \pm 0.001$ & $89 \%$ & $68 \%$ & $77 \%$ \\
\hline
\end{tabular}

a Number of applications.

b The decline was calculated as the difference of the residues in comparison to the previous PHI.

c Increase was calculated based on the comparison with the previous pattern with application of $150 \mathrm{~g}$ a.i/ha.

d Increase was calculated based on the comparison with the previous pattern with 2 applications.

e In these cases, residues at the GAP with 3 applications were lower than the ones in the pattern with 2 applications despite the addition residue burden due to an additional application.

f In these case, residues at the pattern with double the dose rate were lower than the ones in the pattern with the recommended dose despite the addition residue burden due to high dose. 
Table 5. Exposure calculations based on the FAO/WHO and EFSA approach, following the authorized GAP (1 x $75 \mathrm{~g}$ a.i/ha).

\begin{tabular}{l|c|c|c|c|c}
\hline \multirow{2}{*}{$\begin{array}{l}\text { PHI } \\
\text { (days) }\end{array}$} & $\begin{array}{c}\text { C } \\
(\mathrm{mg} \mathrm{kg}-1)\end{array}$ & $\begin{array}{c}|c| \\
\mathrm{NEDl} \\
(\mathrm{mg} / \mathrm{kg} \mathrm{bw} / \mathrm{d})\end{array}$ & RQ & Highest \% of ADI & Highest \% of ARfD \\
\cline { 2 - 5 } & 0.67 & $3.89 \times 10^{-4}$ & 0.02 & 4.0 & 44 \\
0 & 0.58 & $3.38 \times 10^{-4}$ & 0.01 & 4.0 & 38 \\
3 & 0.20 & $1.18 \times 10^{-4}$ & $<0.01$ & 1.0 & 13 \\
7 & 0.041 & $2.39 \times 10^{-5}$ & $<0.01$ & 0.3 & 3 \\
10 & 0.018 & $1.05 \times 10^{-5}$ & $<0.01$ & 0.1 & 0.2 \\
\hline
\end{tabular}

${ }^{a}$ consumption of cucumbers (34,92 gr/bw/day or $0.0349 \mathrm{kgr} / \mathrm{bw} /$ day was used.

feasible with the default value of $0.01 \mathrm{mg}$ $\mathrm{kg}^{-1}$. Applying the authorized GAP and based on the sampling points, residue levels in $\mathrm{Cu}$ cumbers can be considered compliant with this value after 14 days and from the dissipation pattern, after 11 days residues can be expected to be at $0.01 \mathrm{mg} \mathrm{kg}^{-1}$ or lower.

Results of dietary consumer risk assessment are presented in Table 5. In all cases, NEDI values were far below the ADI with RQ at or below 0.02. By applying the EFSA PRIMo, the estimated chronic exposure was calculated up to $4 \%$ of the ADI. Using the same model, short term exposure was estimated at $44 \%$ of the ARfD. Based on the above, a chronic and acute risk is not identified. However, it should be noted that the above conclusion is derived from values based on a single independent field trial and although no shortcomings were observed further independent trials would be desirable to have a more robust estimation (Malhat et al,. 2020).

In conclusion, a decline of SPX residues in cucumbers fit a first-order decay process with a calculated $t_{1 / 2}$ of approximately 2 days with almost a complete degradation (<99\%) after 14 days and residues up to $0.003 \mathrm{mg}$ $\mathrm{kg}^{-1}$ when SPX is applied according to the authorized GAP. An increase of the dose level will result in a significant increase of the residue levels, however the contribution of the increase of the number of applications in the residues is uncertain. From the available data, cucumbers treated according to the authorized or higher dose present up to $4 \%$ of the ADI and $44 \%$ of the ARfD using FAO/WHO and EFSA models.

\section{Literature Cited}

Agricultural Pesticide Committee (APC). http://www. apc.gov.eg/en/default.aspx. Accessed 1/2/2020.

Baćmaga, M., Kucharski, J., Wyszkowska, J. 2019. Microbiological and biochemical properties of soil polluted with a mixture of spiroxamine, tebuconazole, and triadimenol under the cultivation of Triticum aestivum L. Environmental Monitoring and Assessment 191 doi:10.1007/s10661-019-7539-4.

BCGlobal's Pesticide Database https://www.bryantchristie.com. e-Pesticide Manual V2.2, 2002.

Buerge, I.J., Krauss, J., López-Cabeza, R., Siegfried, W., Stüssi, M., Wettstein, F.E., Poiger, T. 2016. Stereoselective metabolism of the sterol biosynthesis inhibitor fungicides fenpropidin, fenpropimorph, and spiroxamine in grapes, sugar beets, and wheat. Journal of Agricultural and Food Chemistry, 64: 5301-5309 doi:10.1021/acs. jafc.6b00919.

Codex Pesticides Residues in Food Online Database http://www.fao.org/fao-who-codexalimentarius/codex-texts/dbs/pestres/en/.

Commission E. 2017. Guidance document on analytical quality control and method validation procedures for pesticide residues and analysis in food and feed.

David, A., Botías, C., Abdul-Sada, A., Goulson, D., Hill, E.M. 2015. Sensitive determination of mixtures of neonicotinoid and fungicide residues in pollen and single bumblebees using a scaled down QuEChERS method for exposure assessment. Analytical and Bioanalytical Chemistry, 407(26): 8151-62. doi: 10.1007/s00216-015-8986-6. Epub 2015 Sep 2. PMID: 26329280.

D’Aquino, S., Barberis, A., Schirra, M., Palma, A. 2011. 
Curative activity of spiroxamine against green mold in citrus fruit. In: 6th International CIGR Technical Symposium - Towards a Sustainable Food Chain: Food Process, Bioprocessing and Food Quality Management.

EN-15662 2009. Foods of plant origin -Determination of pesticide residues using GC-MS and/ or LC-MS/MS following acetonitrile extraction/ partitioning and clean-up by dispersive SPE -QuEChERS-method English version of DIN EN 15662: 2009-2002

European Commision 1995. Storage stability of residue trials 7032-VI-95 rev.5.

European Commission 2013. Commission Regulation (EU) No 283/2013 of 1 March 2013 setting out the data requirements for active substances, in accordance with Regulation (EC) No $1107 / 2009$ of the European Parliament and of the Council concerning the placing of plant protection products on the market.

European Commision 2016. Appendix D. Guidelines on comparability, extrapolation, group tolerances and data requirements for setting MRLs. 7525/VI/95-rev.10.3.

European Commission 2016. Regulation (EU) 2016/452 of 29 March 2016 amending Annexes II and III to Regulation (EC) No 396/2005 of the European Parliament and of the Council as regards maximum residue levels for captan, propiconazole and spiroxamine in or on certain products.

European Commission 2020. EU Pesticide Database. https://ec.europa.eu/food/plant/pesticides/eupesticides-database/public/?event=homepage \&language $=E N$. Accessed 01/02/2020.

European Food Safety Authority 2010. Conclusion on the peer review of the pesticide risk assessment of the active substance spiroxamine. EFSA Journal, 8: 1719.

European Food Safety Authority 2015. Reasoned opinion on the review of the existing maximum residue levels (MRLs) for spiroxamine according to Article 12 of Regulation (EC) No 396/2005. EFSA Journal, 13(1): 48.

European Food Safety Authority 2019. Pesticide Residue Intake Model-EFSA PRIMo revision 3.1 EFSA Supporting Publications 16 doi:10.2903/ sp.efsa.2019.EN-1605.

European Food Safety Authority 2020. The 2018 European Union report on pesticide residues in food. EFSA Journal, 18(4): 6057, 103 pp. https:// doi.org/10.2903/j.efsa.2020.6057.

FAO 2009. Submission and evaluation of pesticide residues data for the estimation of maximum residue levels in food and feed : pesticide residues. FAO plant production and protection papers; 197., vol Accessed from http://nla.gov.au/ nla.cat-vn4931798. Food and Agriculture Organization of the United Nations, Rome.

FAO/WHO 1988. Guidelines for predicting the di- etary intake of pesticide residues Bulletin of the World Health Organization, 66: 429-434.

Ferrer, C., Lozano, A., Agüera, A., Girón, A.J., Fernández-Alba, A.R. 2011. Overcoming matrix effects using the dilution approach in multiresidue methods for fruits and vegetables. Journal of Chromatography A, 1218:7634-7639 doi:https:// doi.org/10.1016/j.chroma.2011.07.033.

FAOSTAT: Food and agriculture data 2015. http:// faostat3.fao.org/faostat-gateway/go/to/down$\operatorname{load} / \mathrm{Q} / * / \mathrm{E}$.

Hellenic Ministry of Rural Development and Food Dopppb List of Authorized Plant Protection Products \& Biocides.

IEDI 2014. IEDI Calculations for FAO/WHO Acute Dietary Intake Assessment.

International union of pure adn applied chemistry (IUPAC). https://iupac.org.

Kmellár, B., Fodor, P., Pareja, L., Ferrer, C., Martínez-Uroz, M., Valverde, A., Fernandez-Alba, A. 2008. Validation and uncertainty study of a comprehensive list of 160 pesticide residues in multi-class vegetables by liquid chromatography-tandem mass spectrometry. Journal of Chromatography A, 1215: 37-50.

Malhat, F., Saber E.-S., Amin, A.S., Anagnostopoulos, C., Abdelsalam Shokr, S. 2020. Magnitude of picoxystrobin residues in strawberry under Egyptian conditions: dissipation pattern and consumer risk assessment. Food Additives and Contaminants: Part A: 1-10 doi:10.1080/1944004 9.2020.1736342.

Miller, T.C and Gubler W.D. 2004. Sensitivity of California isolates of Uncinula necator to trifloxystrobin and spiroxamine, and update on triadimefon sensitivity. Plant Disease, 88: 1205-1212 doi:10.1094/PDIS.2004.88.11.1205.

OECD 2007. Test No 506: Stability of Pesticide Residues in Stored Commodities. Guidelines for the Testing of Chemicals, . Paris. doi:doi:https://doi. org/10.1787/9789264061927-en.

OECD 2009. Test No. 509: Crop Field Trial vol Section 5, . Guidelines for the Testing of Chemicals, . OECD Publishing, Paris. doi:doi:https://doi. org/10.1787/9789264076457-en.

Pereira, V.L., Fernandes, J.O., Cunha, S.C. 2014. Mycotoxins in cereals and related foodstuffs: A review on occurrence and recent methods of analysis. Trends in Food Science and Technology, 36: 96-136.

Pizzutti, I.R, de Kok, A, Hiemstra, M., Wickert, C., Prestes, O.D. 2009. Method validation and comparison of acetonitrile and acetone extraction for the analysis of 169 pesticides in soya grain by liquid chromatography-tandem mass spectrometry. Journal of Chromatography A, 1216: 4539-4552.

Rosales-Conrado, N. 2009. Hydrolysis study and extraction of spiroxamine from soils of different 
physico-chemical properties. Chemosphere, 77: 821-828 doi:10.1016/j.chemosphere.2009.07.078.

SANTE/11813/2017. 2017. Guidance document on analytical quality control and method validation procedures for pesticide residues and analysis in food and feed.

Sukul, P., Zuhlke, S., Lamshoft, M., Rosales-Conrado, N., Spiteller, M. 2010. Dissipation and metabolism of (14)C-spiroxamine in soil under laboratory condition. Environmental Pollution, 158: 15421550 doi:10.1016/j.envpol.2009.12.025.

Tokatlı, C, Köse, E, Çiçek, A, Emiroğlu, Ö., Tokatlı, C. 2020. Pesticide accumulation in Turkey's Meriç river basinwater and sediment. Polish Journal of Environmental Studies, 29(1): 1003-1008.

Tosi, S., Costa, C., Vesco, U., Quaglia, G., Guido, G. 2018. A 3-year survey of Italian honey bee-collected pollen reveals widespread contamination by agricultural pesticides. Science of the Total Environment, 615: 208-218.

Tsiropoulos, N.G., Liapis, K., Likas, D., Miliadis, G. 2005a Determination of Spiroxamine Residues in Grapes, Must, and Wine by Gas Chromatography/Ion Trap-Mass Spectrometry. Journal of AOAC International, 88(6): 1834-1839.

Tsiropoulos, N.G, Miliadis, G., Likas, D., Liapis, K. 2005b. Residues of Spiroxamine in Grapes Following Field Application and Their Fate from
Vine to Wine. Journal of Agricultural and Food Chemistry, 53: 10091-10096.

Wang, Z., Cang, T., Qi, P., Zhao, X., Xu, H., Wang, X., Zhang, H. 2015. Dissipation of four fungicides on greenhouse strawberries and an assessment of their risks. Food Control, 55: 215-220 doi:10.1016/j.foodcont.2015.02.050.

WHO 2013a. GEMS/food regional diets (regional percapita consumption of raw and semi-processed agricultural commodities).

WHO 2013b. Global Environment Monitoring System - Food Contamination Monitoring and Assessment Programme (GEMS/Food).

Zhu Xiaodan, Jia Chunhong, Duan Lifang, Zhang Wei, Yu Pingzhong, Ercheng, Z. 2016. Residue behavior and dietary intake risk assessment of three fungicides in tomatoes (Lycopersicon esculentum Mill.) under greenhouse conditions. Regulatory Toxicology and Pharmacology, 81: 284287.

Received: 2 March 2021; Accepted: 1 December 2021

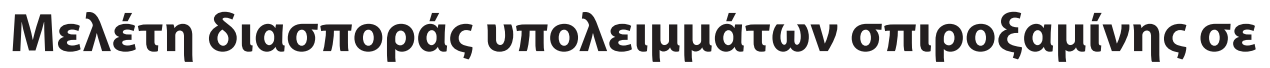

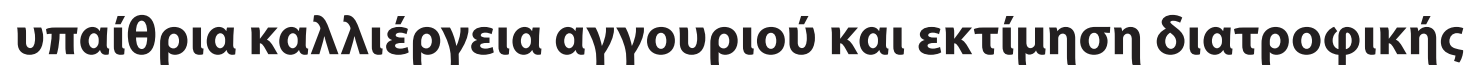

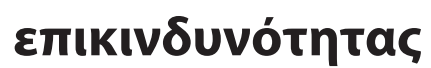

\section{F. Malhat, Ch. Anagnostopoulos, S. El-Sayed kaı S. Abdelsalam Shokr}

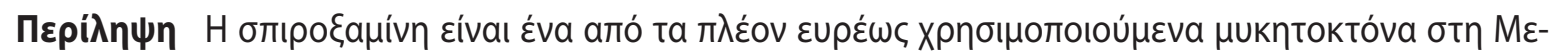

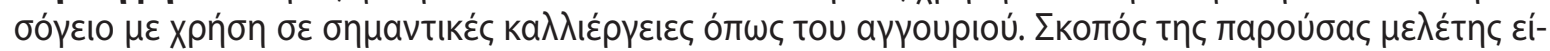

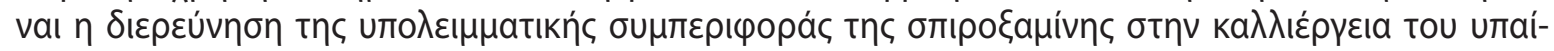

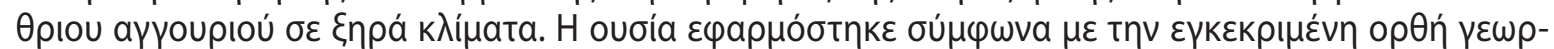

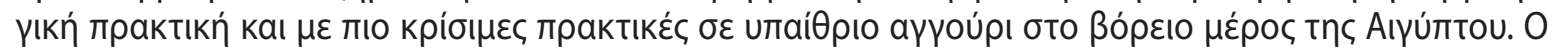

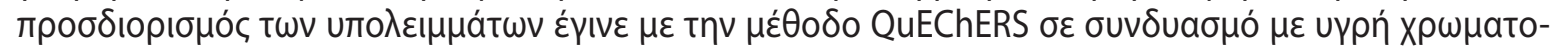

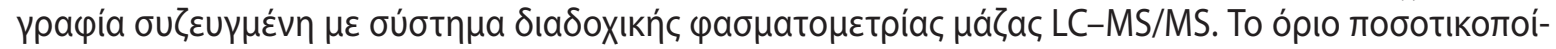

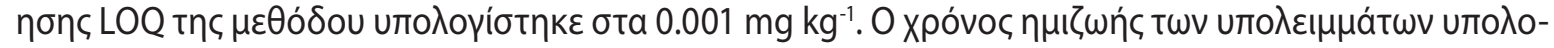

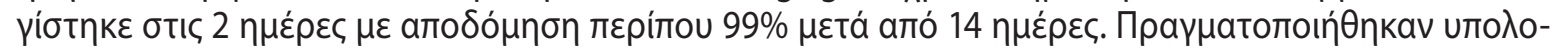

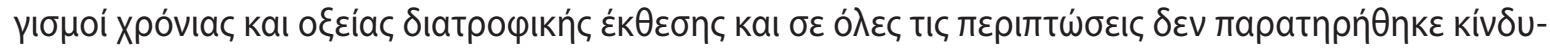

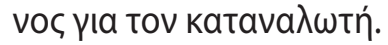

Hellenic Plant Protection Journal 15: 40-48, 2022 